\title{
Human Keratinocytes Produce but do not Process Pro-Interleukin-1 (IL-1) Beta Different Strategies of IL-1 Production and Processing in Monocytes and Keratinocytes
}

\author{
H. Mizutani, R. Black, ${ }^{\star}$ and T. S. Kupper \\ Division of Dermatology, Departments of Medicine and Pathology, Washington University School of Medicine, \\ St. Louis, Missouri 63110; and *Department of Protein Chemistry, Immunex Corporation, Seattle, Washington 98101
}

\begin{abstract}
Keratinocytes comprise the majority of cells in the epidermis, the interleukin-1 rich layer of tissue contiguous with the outside world. Keratinocytes produce IL-1 $\alpha$ and $\beta$ mRNA in vitro, but only IL-1 $\alpha$ biological activity has been identified in keratinocyte cultures. In contrast, monocytes secrete biological activities attributable to both species of IL-1. Using several monoclonal antibodies to IL-1 $\beta$, significant amounts of IL-1 $\beta$ protein could be found in keratinocyte cultures; all of this immunoreactive IL-1 $\beta$ was in the 31-kD form. This latent cytokine has been shown to bind inefficiently to the IL-1 receptor and to be (in relative terms) biologically inactive. Chymotrypsin cleaves 31 kD IL-1 $\beta$ at Tyr 113-Val 114, generating an 18-kD IL-1 species with activity equivalent to the authentic mature IL-1 $\beta$ ( $\mathrm{NH}_{2}$-terminal Ala 117). Treatment of 31-kD keratinocyte IL$1 \beta$ with chymotrypsin also generated an $18-\mathrm{kD}$ molecule and significant IL-1 activity. Monocytes contain an IL-1 convertase enzyme that cleaves the IL-1 $\beta$ promolecule at Ala 117. We demonstrate here that keratinocytes do not contain such an IL-1 convertase activity, nor do they contain any activity capable of productively processing 31-kD IL-1 $\beta$ into a biologically active form. These data suggest that keratinocytes (and other non-bone marrow-derived cells) produce $\mathrm{IL-1} \beta$ in an inactive form that can be processed only after leaving the cell. (J. Clin. Invest. 1991. 87:1066-1071.) Key words: IL-1 • cytokines • convertase $\bullet$ epidermis $\bullet$ inflammation
\end{abstract}

\section{Introduction}

The recent observation that nearly every cell type examined can produce interleukin $1 \alpha$ and/or $\beta$ mRNA in vitro after appropriate induction $(1,2)$ has forced a reevaluation of the role of IL-1 in immune and inflammatory processes. A complicating factor is the observation that the detection of mRNA for an IL-1 species does not necessarily indicate that a biologically active protein is being produced (1-4). In this study, we address this phenomenon and the paradox of IL-1 production by human epidermal keratinocytes. Keratinocytes contain mRNAs identical to monocyte IL- $1 \alpha$ and $\beta$ mRNA (4-6), and these mRNAs can be induced to accumulate by various stimuli ( 7 ,

Address correspondence and reprint requests to Dr. Thomas S. Kupper, Division of Dermatology, Departments of Medicine and Pathology, Washington University School of Medicine, 660 South Euclid Avenue, Box 8123, St. Louis, MO 63110.

Received for publication 20 July 1990 and in revised form 24 September 1990.

J. Clin. Invest.

(c) The American Society for Clinical Investigation, Inc.

0021-9738/91/03/1066/06 \$2.00

Volume 87, March 1991, 1066-1071
8). While these cells synthesize significant amounts of IL-1 $\alpha$ protein that is biologically active, we and others have been unable to demonstrate biological activity attributable to IL- $1 \beta$ $(4,9,10)$. In addition, we and others have found that the prodigious amount of IL-1 activity in normal epidermis is exclusively due to IL-1 $\alpha(10,11)$. In this study, we demonstrate that keratinocytes translate IL- $1 \beta$ pro-mRNA into protein and contain significant amounts of $31-\mathrm{kD}$ IL- $1 \beta$. Furthermore, we show that keratinocytes, unlike monocytes, lack enzymatic activity capable of generating mature $17-\mathrm{kD}$ IL- $1 \beta$ from the precursor molecule. We found that keratinocyte pro-IL-1 $\beta$ can be converted in vitro to a biologically active molecule by exogenous proteases. The significant differences between keratinocytes and monocytes with regard to IL- 1 production and processing are discussed in terms of the discrete role of each cell in host defense. This is the first clear demonstration that natural $31-\mathrm{kD}$ pro-IL-1 $\beta$ lacks significant biological activity until proteolytically processed, and raises important analogies between pro-IL- $1 \beta$ and other latent cytokines.

\section{Methods}

Keratinocytes. Normal human keratinocytes from foreskin or from patients undergoing reconstructive surgery were obtained as described previously $(4,12)$ or purchased from Clonetics Corp. (San Diego, CA) and grown in MCDB 153 medium supplemented as described by Boyce and Ham (13). Cells grown in MCDB 153 were trypsinized and replated on tissue culture plastic before primary cultures reached confluence, and these secondary or tertiary cultures were used for all subsequent studies.

Interleukin 1. Recombinant "mature" or $17-\mathrm{kD}$ human IL-1 $\beta$ encoded by the latter half of the IL- $1 \beta$ cDNA (codons 117-269) was synthesized in a prokaryotic expression vector under control of a temperature sensitive repressor (14). The protein was extracted from Escherichia coli and purified to apparent homogeneity by sequential sulfopropyl sephadex, DEAE, and Procion Red column chromatography (Bethesda Research Laboratories, Gaithersburg, MD) as described (14). Minor modifications of a similar protocol were used to obtain the $17-\mathrm{kD}$ form of IL- $1 \alpha$. Expression of recombinant "precursor", 31-kD, or "pro-IL-1 $\beta$ " involved the use of a full length (codons 1-269) IL-1 $\beta$ cDNA using the same temperature sensitive repressor (15). After lysis of bacteria, 31-kD IL-1 $\beta$ was purified using sequential $Q$ Sepahrose, Procion Red, and Phenyl-Sepharose CL-4B chromatography as previously described (15).

Anti IL-1 antibodies. Monoclonal anti-IL-1 antibodies for immunoblotting (anti-IL-1 $\beta$ M1, M2, M3, and M4, and anti IL-1 $\alpha$ M5) have been previously described (15). Anti-IL-1 $\beta$ monoclonal antibodies for immunoblotting and for ELISA (ANOC 243 and ANOC 205) were also provided by Otsuka Pharmaceutical Co. (Tokushima, Japan). IL-1 $\alpha$ and IL-1 $\beta$ immunoaffinity gels were provided by Endogen (Boston, MA) and were used according to manufacturer's instructions. Briefly, for removal of IL- $1 \alpha$ from the keratinocyte lysate, gels were washed five times with PBS and mixed with NHK lysate. The mixture was incubated and gently mixed for $1 \mathrm{~h}$ at $37^{\circ} \mathrm{C}$, centrifuged, and the IL- $1 \alpha$ supernatant was recovered for further experiments. 
IL-1 biological assay. The assay to detect IL-1 activity utilizes the T cell clone D10.G4.1 and the clonotype-specific monoclonal antibody $3 \mathrm{D} 3$ and has been described in detail $(16,17) .6 \mathrm{~h}$ before harvest $\left[{ }^{3} \mathrm{H}\right]-$ thymidine $(1 \mu \mathrm{Ci}$ per well; $1 \mathrm{Ci}=37 \mathrm{GBq})$ was added. Triplicate cultures were harvested on an automated sample harvester (Cambridge Technologies, Inc., Boston, MA) and radioactivity was measured with an LKB scintillation spectrometer (LKB Instruments, Inc., Gaithersburg, MD).

$I L-1$ ELISA. The IL-1 $\alpha$ ELISA kit was provided by Endogen. The IL- $1 \beta$ ELISA kit was provided by Otsuka Pharmaceutical Co. Assays were done according to manufacturer's instructions. Briefly, purified antibodies were coated on microtiter plates overnight at room temperature. After the plates were blocked by bovine albumin solution for $4 \mathrm{~h}$ and washed and soaked in $0.05 \%$ Tween 20 PBS, samples and serial dilutions of recombinant human IL-1 (rhIL-1) were added and left at $4^{\circ} \mathrm{C}$ overnight. After washing, purified anti-IL-1 rabbit serum was added for $2 \mathrm{~h}$ and washed again. Goat anti-rabbit IgG antibodies coupled to peroxidase were added for an additional $2 \mathrm{~h}$ and peroxidase activity was developed by using $\mathrm{H}_{2} \mathrm{O}_{2}$-ortho-phenylenediamine substrate.

Immunoblotting. Samples (affinity purified or freshly isolated keratinocyte lysate) were loaded on to a $13 \%$ polyacrylamide gel containing $0.1 \%$ SDS under reducing or nonreducing conditions. After electrophoresis, proteins were transferred onto nitrocellulose membrane (BioRad Laboratories, Richmond, CA) in a trans-blot cell apparatus (BioRad Laboratories). The blot was blocked with dry milk and then incubated for $1 \mathrm{~h}$ with monoclonal anti-IL-1 antibody (see above) diluted in $0.05 \%$ Tween $2010 \mathrm{mM}$ Tris-buffer (ph 8.0) (TBST). After washing in TBST, alkaline phosphatase-conjugated goat anti-mouse IgG antibody (Promega Biotec, Madison, WI) was added and the blot was developed and photographed.

\section{Results}

Conditioned medium from keratinocytes grown under conditions that inhibit or promote differentiation do not contain sufficient IL- 1 to measure in either the IL- $1 \alpha$ or $\beta$ ELISA system (not shown). These results are consistent with the observation that under most conditions, the vast majority of IL-1 present in keratinocyte cultures is cell associated (7). Sonicated lysates of keratinocytes were tested for IL- $1 \alpha$ and $\beta$ in the appropriate ELISA. Results are shown in Fig. 1. Comparable amounts of IL- $1 \alpha$ and $\beta$ can be detected in such lysates, and the short term conditions of growth as they relate to state of differentiation, calcium concentration, or fetal calf serum do not effect the IL- 1 content of keratinocytes. The amounts of IL- $1 \alpha$ and $\beta$ varied between different isolates of keratinocytes, but were both generally between $2-10 \times 10^{-16} \mathrm{~g} /$ cell, or $0.36-1.8$ $\times 10^{4}$ molecules of IL-1 species/cell. Western blot analysis of recombinant mature and pro-IL-1 $\beta$, using the capture (first

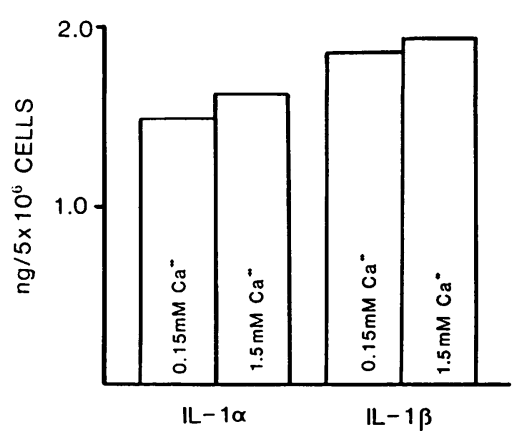

Figure 1. Comparison of immunoreactive IL$1 \alpha$ and IL- $1 \beta$ in cultured keratinocytes grown under normal $(1.5 \mathrm{mM})$ or low $(0.15$ $\mathrm{mM}$ ) calcium conditions. No significant differences were appreciated between groups after 48 $h$ of culture in the above conditions. step) antibody in an ELISA kit obtained from Otsuka Pharmaceutical Co., showed that the monoclonal antibody clearly recognizes both species, indicating that the IL- $1 \beta$ ELISA should detect both mature and pro-IL-1 $\beta$ (not shown).

The molecular weight of cell-associated IL-1 was determined by Western blotting. Lysates of keratinocytes were electrophoresed under reducing and nonreducing conditions and analyzed using monoclonal antibodies to either IL- $1 \alpha$ or IL- $1 \beta$. Under nonreducing conditions, mature rIL-1 $\beta$ often appeared in a dimeric form. This occurred minimally (or not at all) when gels were run under reducing conditions, regardless of the antibody used for Western blotting. Keratinocyte lysate material immunoreactive with IL- $1 \beta$ antibodies migrated in a fashion similar to pro-IL- $\beta$ at $31 \mathrm{kD}$. No immunoreactivity was seen in the range of $17 \mathrm{kD}$, where the majority of recombinant mature IL- $1 \beta$ migrates. A similar pattern was seen using monoclonal antibodies directed at different epitopes on the IL- $1 \beta$ molecule, suggesting that these immunoreactive bands represented authentic IL-1 (Fig. 2, $A-C$ ). This was true for all antibodies under reducing and nonreducing conditions. That this occurred even after cell lysis suggested that minimal proteolytic activity for pro-IL- $1 \beta$ exists in keratinocytes, and that cell-associated IL- $1 \beta$ exists as a pro-molecule in keratinocytes. IL- $1 \alpha$ antibodies also detected a $31-\mathrm{kD}$ species (consistent with our previous results, as described in reference 8 ) (Fig. 3). It should be noted that previous reports have suggested the pro- and mature IL- $1 \alpha$ and mature IL- $1 \beta$ have comparable IL- 1 bioactivity, while pro-IL- $1 \beta$ has little if any activity $(15,18)$.

The results of the Western blotting experiments suggested that the explanation for the lack of IL- $1 \beta$ biological activity in keratinocyte cultures was the existence of IL- $1 \beta$ exclusively in a precursor form. If true, we reasoned that we should be able to generate a lower molecular weight IL- $1 \beta$ with enhanced biological activity by treating keratinocyte lysates with an appropriate protease. As an initial approach, we treated recombinant proIL- $1 \beta$ with alpha-chymotrypsin, a protease previously shown to cleave recombinant pro-IL-1 $\beta$ at Tyr $113-$ Val 114 (15). Fig. 4 indicates that this manuever generates an immunoreactive band which migrates slightly higher than mature recombinant IL- $1 \beta$, consistent with a molecule three amino acids longer than mature IL-1 $\beta$. Fig. 5 demonstrates that in the D10 assay, chymotrypsin itself has no activity. At $160 \mathrm{pg} / \mathrm{ml}$, recombinant pro-IL- $1 \beta$ has no significant activity in this assay either, consistent with previous reports $(15,18)$. However, the addition of chymotrypsin to recombinant pro-IL- $1 \beta$ generates significant activity in the D10 assay, comparable to similar amounts of mature IL-1 $\alpha$ (column 4 ) or mature IL-1 $\beta$ (not shown). These experiments confirmed that pro-IL- $1 \beta$ had little biological activity, but indicate that its chymotrypic digest has significant biological activity.

In the next series of experiments, keratinocyte lysates were treated with chymotrypsin in parallel with recombinant proIL- $1 \beta$, and the digests were analyzed by Western blotting. Fig. 6 indicates that chymotrypsin converts recombinant pro-IL- $1 \beta$ to a molecule that migrates slightly higher than recombinant mature IL- $1 \beta$, and in this experiment, an additional immunoreactive band of $\sim 5 \mathrm{kD}$ was generated. Keratinocyte lysates containing the immunoreactive species which comigrates with recombinant pro-IL-1 $\beta$ were similarly treated. The digestion with chymotrypsin caused a significant diminution in the intensity of this band, with the coincident emergence of immuno- 

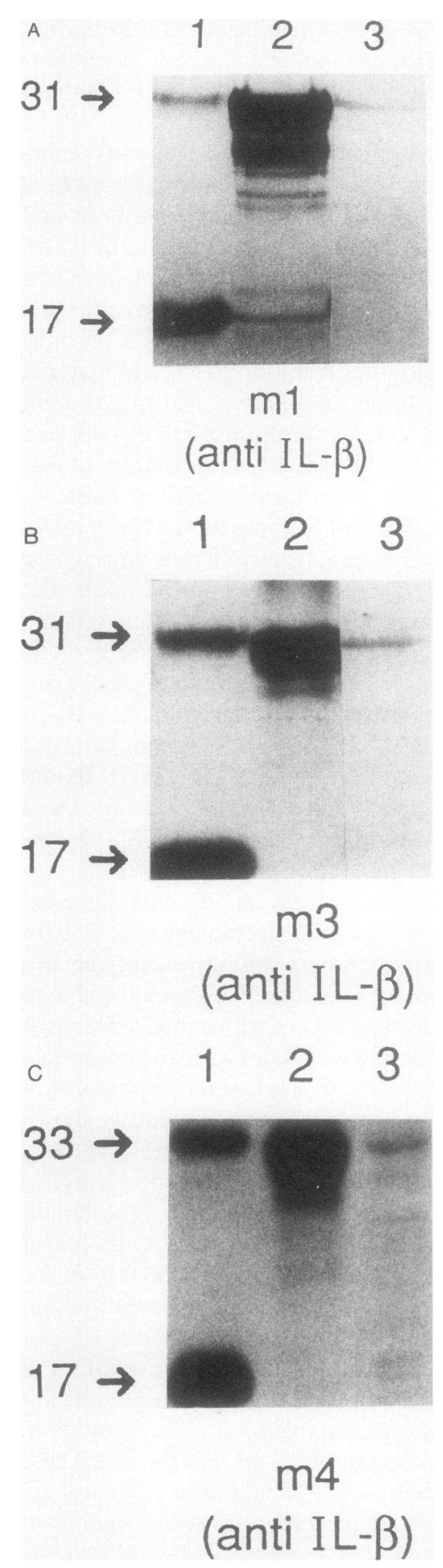

Figure 2. Western analysis of keratinocyte lysates using different monoclonal antibodies to $\mathrm{IL}-1 \beta$. $(A) \mathrm{M} 1$ antibody, reducing conditions; lane 1,17 kD IL-1 $\beta$; lane 2, 31-kD IL- $1 \beta$; lane 3 , keratinocyte lysate. $(B)$ M3 antibody, nonreducing conditions; lane $1,17-\mathrm{kD}$ IL-1 $\beta$; lane $2,31-\mathrm{kD}$ IL-1 $\beta$; lane 3 , keratinocyte lysate. $(C)$ M4 antibody, nonreducing conditions; lane $1,17-\mathrm{kD}$ IL-1 $\beta$; lane $2,31-\mathrm{kD}$ IL-1 $\beta$; lane 3 , keratinocyte lysate.

reactive bands that comigrate with the bands found in the recombinant pro-IL-1 $\beta$ chymotrypic digest ( 18 and $5 \mathrm{kD}$ ). This strongly suggests that the immunoreactive band at $31 \mathrm{kD}$ in the keratinocyte lysate represents authentic pro-IL- $1 \beta$.

To demonstrate that chymotryptic digestion of keratinocyte lysates generated a biologically active IL- $1 \beta$, it was first necessary to remove the IL- $1 \alpha$ from these lysates. This was accomplished using an immunoaffinity agarose gel coupled to IL-1 $\alpha$ antibodies (Endogen) (see Methods). Fig. 7 demonstrates

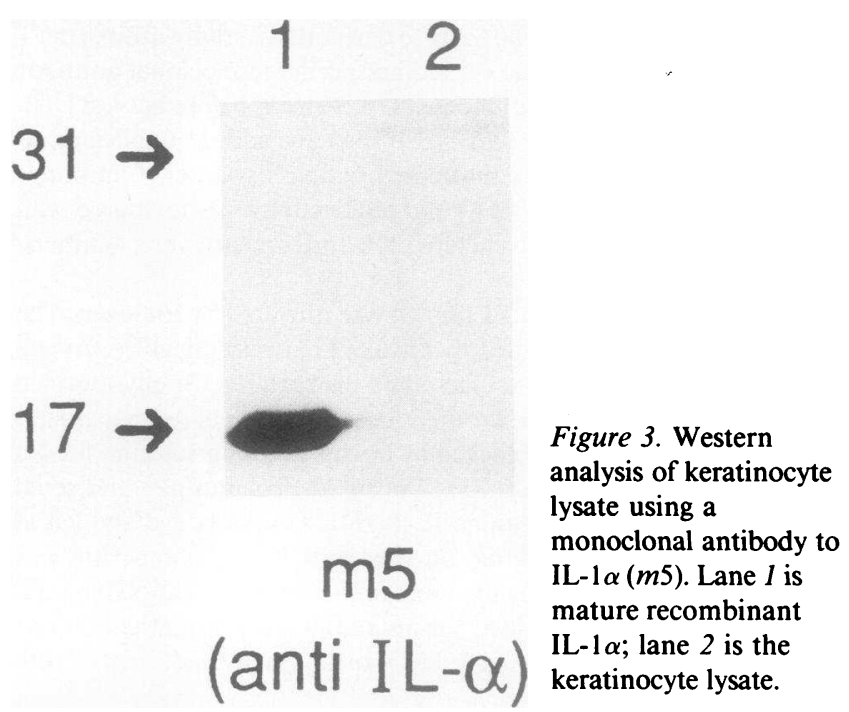

that while keratinocyte (NHK) lysates contain significant IL-1 activity, incubation with the affinity gel specific for IL- $1 \alpha$ led to a virtually complete abrogation of this activity. The efficacy of this gel in the removal of IL- $1 \alpha$ was confirmed by ELISA (not shown). This result confirmed previous reports that IL-1 biological activity in keratinocyte cultures is attributable to IL- $1 \alpha(4$, $10,11)$. This IL-1 $\alpha$-depleted keratinocyte lysate was then treated with chymotrypsin under conditions identical to those used for the experiment shown in Fig. 6. Chymotrypsin treatment generated significant activity in the D10 assay, and treatment of a mock IL- $1 \alpha$-depleted lysate with chymotrypsin also led to a significant increase in the amount of IL-1 activity. The activity in both lysates could be substantially blocked with antibodies to IL-1 $\beta$ (not shown).

Since keratinocyte pro-IL-1 $\beta$ was susceptible to proteolytic cleavage by exogenous proteases, and since this proteolytic digestion led to the generation of biological activity, these experiments suggested an intrinsic absence of specific protease activity for pro-IL-1 $\beta$ in keratinocytes. In contrast, monocytes contain a coinducible protease that can cleave pro-IL-1 $\beta$ at ala 117 . Fig. 8 shows that THP-1 lysates (lane 2) contain immunoreactive IL- $1 \beta$ species that migrate in a fashion identical to recombinant $31-\mathrm{kD}$ IL-1 $\beta$ (lane 1 ) and 17 -kD IL-1 $\beta$ (lane 6 ). The addition of this lysate to $31-\mathrm{kD}$ IL- $1 \beta$ leads to a substantial increase of $17-\mathrm{kD}$ material with a commensurate decrease in material at $31-\mathrm{kD}$, indicating the presence of the convertase enzyme. Further confirmation was obtained by analysis of a 1:12 dilution of

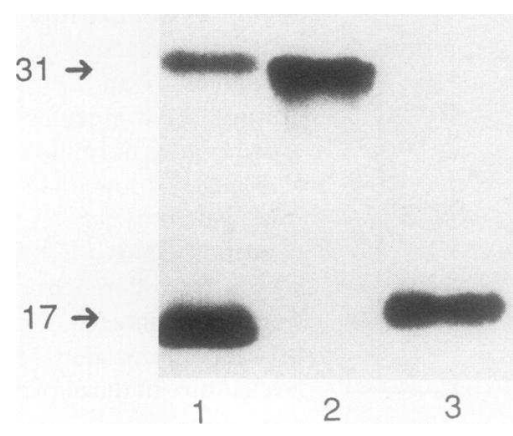

Figure 4. Western analysis of recombinant pro-IL- $1 \beta$ treated with alpha-chymotrypsin (see Methods). Lane 1, recombinant mature IL- $1 \beta$; lane 2 , recombinant pro-IL-1 $\beta$; lane 3 , chymotryptic digest of recombinant pro-IL-1 $\beta$. 


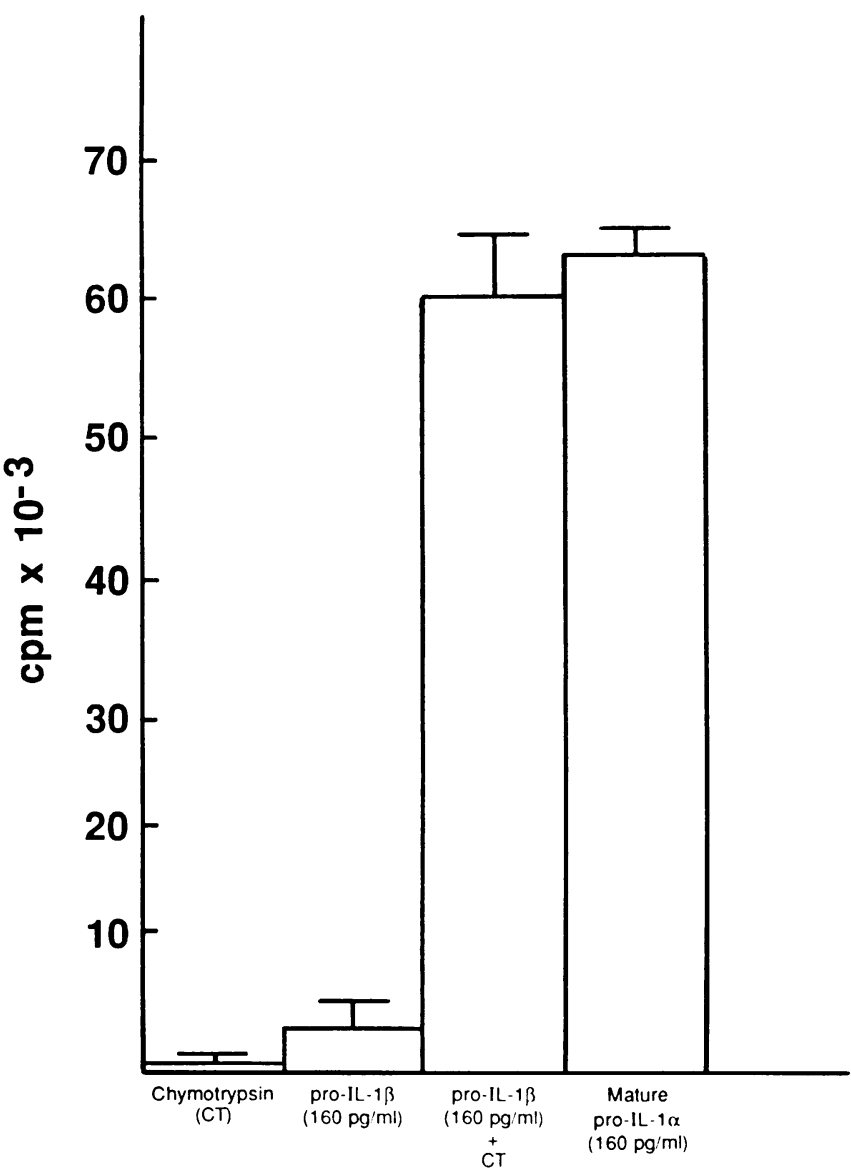

Figure 5. D10 assay of untreated and chymotrypsin treated recombinant pro-IL-1 $\beta$. Chymotrypsin itself has no D10 stimulating activity. Pro-IL- $1 \beta$ has little activity; however, after chymotrypsin digestion, significant activity is generated.

the same THP-1 lysate (lane 4), in which virtually no material is detectable at $17 \mathrm{kD}$. The addition of this lysate to $31-\mathrm{kD}$ IL- $1 \beta$ similarly led to the appearance of $17-\mathrm{kD}$ IL- $1 \beta$ and a decrease in $31-\mathrm{kD}$ IL- $1 \beta$ (lane 5), further confirming the presence of the convertase enzyme. Previous work has shown that this convertase enzyme cleaves 31-kD IL- $1 \beta$ at Asp1 16-Ala 117 (19-21).

Similar experiments were attempted with cultured keratinocyte lysates. Fig. 9 shows a representative experiment wherein lysates from keratinocytes from cultures grown under low $(0.15 \mathrm{mM})$ and high $(1.5 \mathrm{mM})$ calcium conditions (lanes 2

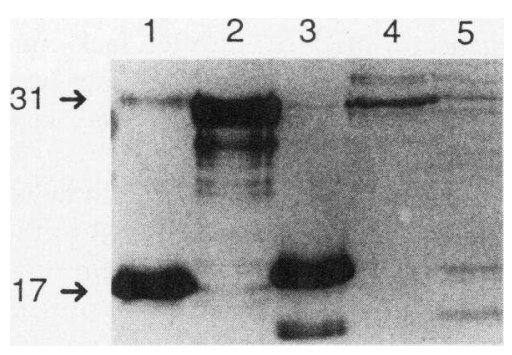

Figure 6. Western analysis of keratinocyte lysates and recombinant pro-IL- $1 \beta$ before and after chymotrypsin digestion (see Methods). Lane 1 , recombinant mature IL- $1 \beta$; lane 2 recombinant pro-IL-1 $\beta$; lane 3 , chymotrypsin digest of r-pro-IL-1 $\beta$;

lane 4 , keratinocyte lysate; lane 5 , chymotryptic digest of keratinocyte lysate.

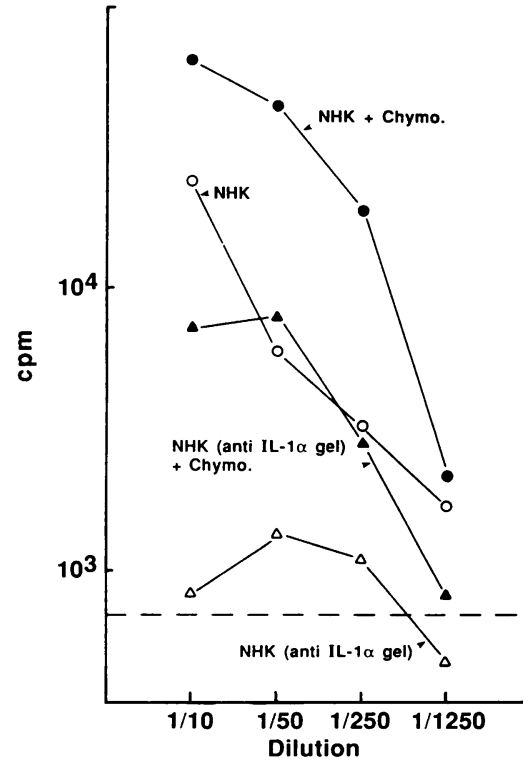

and 4 , respectively) contained material that migrated similarly to $31-\mathrm{kD}$ IL- $1 \beta$ (lane 1 ). The addition of $31-\mathrm{kD}$ IL- $1 \beta$ to low calcium keratinocyte lysates (lane 3 ) or to high calcium keratinocyte lysates (lane 5) did not lead to the generation of a detectable $17-\mathrm{kD}$ species. The pattern of immunoreactive species in the $31-\mathrm{kD}$ IL- $1 \beta$ preparation did not change detectably in the presence of either keratinocyte lysate, indicating that these cells do not contain protease activity capable of digesting $31-\mathrm{kD}$ IL-1 $\beta$ under these experimental conditions. Additional experiments have indicated that regardless of inductive stimuli, keratinocytes do not contain detectable convertase activity, though certain stimuli result in protease activity capable of generating small amounts of immunoreactive material that migrates at $20 \mathrm{kD}$. This proteolytic product of $31-\mathrm{kD}$ IL- $1 \beta$ is similar to that predicted by elastase cleavage (15), a protein with little biological activity compared with mature $17-\mathrm{kD}$ IL$1 \beta$. Experiments are underway to confirm the absence of monocyte convertase in keratinocytes using recently isolated cDNAs for this enzyme.

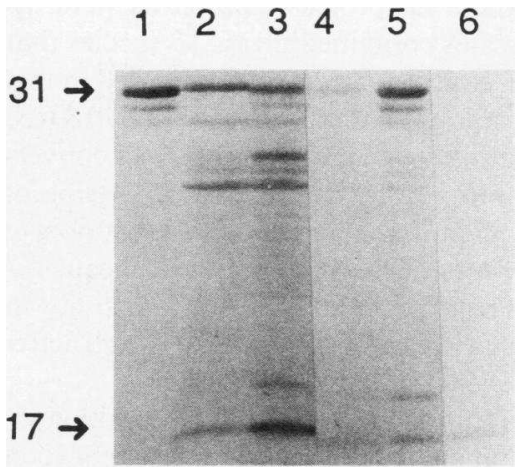

Figure 8. Western analysis of $31-\mathrm{kD} \mathrm{IL-} \beta$ exposed to monocyte convertase activity. Lane 1, 31-kD IL-1 $\beta$; lane 2, THP-1 monocyte lysate; lane 3 , 31-kD IL- $1 \beta$ incubated with THP-1 lysate; lane 4, 1:12 dilution of THP-1 lysate; lane 5 , 31-kD IL- $1 \beta$ incubated with $1: 12$ dilution of THP-1 lysate; lane 6, 17-kD IL-1 $\beta$. 


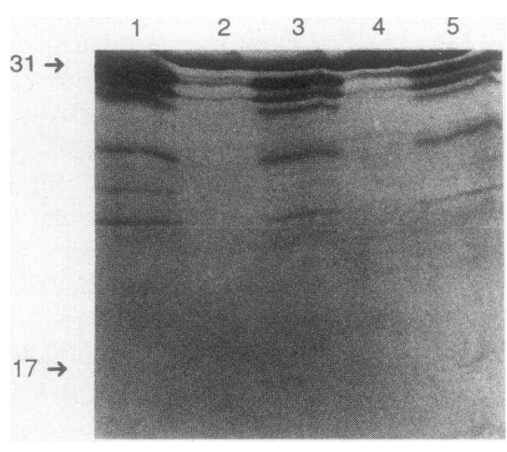

Figure 9. Western analysis of $31-\mathrm{kD}$ IL-1 $\beta$ exposed to keratinocyte lysates. Lane 1, 31-kD IL-1 $\beta$; lane 2 , keratinocyte lysate $(0.15$ $\mathrm{mM} \mathrm{Ca}^{2+}$ ); lane 3, 31kD IL- $1 \beta$ incubated with keratinocyte lysate $\left(0.15 \mathrm{mM} \mathrm{Ca}^{2+}\right)$; lane 4 , keratinocyte lysate $\left(1.5 \mathrm{mM} \mathrm{Ca}^{2+}\right)$; lane 5 , 31-kD IL- $1 \beta$ incubated with keratinocyte lysate $\left(1.5 \mathrm{mM} \mathrm{Ca}^{2+}\right)$.

\section{Discussion}

Upon stimulation in vitro, monocytes produce significant amounts of IL- $1 \alpha$ and $\beta$ mRNA and protein, and convert proIL- $1 \beta$ to a mature biologically active species using at least one distinct protease $(1,2,19-21,24)$. A significant amount of both immature and mature IL- $1 \beta$ is secreted from the cell in a poorly understood fashion $(24,25)$, while the majority of IL- $1 \alpha$ remains in a cell-associated compartment $(23,24,26,27)$. In direct contrast, cultured fibroblasts do not express IL- $1 \alpha$ mRNA and express IL- $1 \beta$ mRNA only after exogenous stimulation (3). Further signals are required for the translation of this mRNA (3), and the pro-IL- $1 \beta$ thus produced has not been shown to be converted to a mature molecule $(3,22,23)$. This study suggests the basis of a third strategy of IL-1 production that is exhibited by the cultured keratinocyte that produces significant biologically active IL- $1 \alpha$ protein but does not produce biologically active IL- $1 \beta$ protein.

We have demonstrated that despite the lack of biological activity attributable to IL- $1 \beta$, cultured keratinocytes contain significant amounts of a protein that is identical to pro-IL- $1 \beta$ by several criteria. First, keratinocyte pro-IL-1 $\beta$ comigrates with recombinant pro-IL-1 $\beta$, and can be detected by ELISA and Western blot analysis using several monoclonal antibodies directed at different epitopes on the IL-1 $\beta$ molecule. Second, the chymotryptic digest of keratinocyte IL-1 comigrates with the chymotryptic digest of recombinant pro-IL-1 $\beta$, and in both digests a band which migrates slightly higher than authentic mature IL- $1 \beta$ can be demonstrated. Finally, while neither IL$1 \alpha$-depleted keratinocyte lysate nor recombinant pro-IL- $1 \beta$ have significant activity in IL-1 bioassays, their chymotryptic digests contain substantial biological activity.

It is of interest that even if keratinocyte lysates were generated under conditions where no protease inhibitors were included in the mixture, lysates contained no IL- $1 \beta$ species that migrated below $31 \mathrm{kD}$. In contrast, monocytes prepared in this fashion show significant amounts of mature 17-kD IL-1 $\beta$ (see Fig. 8). While this observation suggested a lack of IL- $1 \beta$ convertase activity, this was confirmed by the lack of processing of recombinant pro-IL-1 $\beta$ when it was mixed with keratinocyte lysates. Parallel lysates of monocytes contained significant IL$1 \beta$ convertase activity. The absence of convertase activity in keratinocytes is consistent with a similar absence of such activity in various fibroblast lines (20).

Why do cells which cannot process pro-IL- $1 \beta$ into a biologically active species expend the energy to produce it? Several possibilities exist. First, pro-IL-1 $\beta$ may have an intracellular role which is independent of its capacity to bind to the cell surface IL-1 receptor. For example, reports that IL- $1 \beta$ is myristoylated, and evidence that myristoyl proteins perform important intracellular functions (27), suggest that this is at least a hypothetical role for intracellular IL-1 $\beta$. Second, it may be that the failure of us and others to detect processing of pro-IL- $1 \beta$ is an artifact of in vitro culture systems. Finally (and the interpretation we favor), IL-1 $\beta$ produced by cells such as fibroblasts and keratinocytes may serve as a potential substrate for extracellular proteases after cell injury or death. Specifically, pro-IL$1 \beta$ released by injured or dying cells could be converted to active IL- $1 \beta$ in the extracellular space by inflammatory cell proteases, thus activating uninjured resident cells to produce IL-1-inducible cytokines, which attract and activate cells of the immune and inflammatory systems, e.g., IL-6, IL-8, granulocyte-macrophage (GM)-CSF, and G-CSF (9). That many of the stimuli which induce IL- $1 \beta$ gene expression are injurious $(1,2$, 7) is also consistent with this paradigm.

Keratinocytes are unique in that terminally differentiated cells are "excreted" by desquamation, and thus in the absence of injury their contents do not come in contact with the internal milieu of the body. Therefore, if IL- $1 \alpha$ produced by the keratinocyte in vivo remains in a cell-associated compartment, it is "excreted" with the cell if unused. IL- $1 \alpha$, which is present in prodigious amounts (in biological terms) in normal epidermis (9-11) and does not require proteolytic processing to manifest biological activity, is thus well suited to its epidermal location. Traumatic injury to the skin releases IL- $1 \alpha$, which has immediate effects on contiguous keratinocytes, fibroblasts, and endothelial cells relevant to inflammation and wound healing $(9,11)$. Thus, there is no absolute requirement for the presence of inflammatory cells and their proteases to initiate the generation of IL-1 bioactivity in the injured cutaneous microenvironment. IL- $1 \beta$ produced by keratinocytes, however, must be activated by the products of such inflammatory cells; alternatively, activation of other nonepithelial cells resident to epidermis may lead to protease production. It should be noted that lower molecular weight forms of IL- $1 \beta$ can be identified in psoriatic epidermis (10). The absence of biological activity attributable to IL-1 $\beta$ in psoriatic epidermal samples suggests that nonproductive cleavage of pro-IL-1 $\beta$ does occur in this setting.

There is an accummulating body of evidence that several pleiotropic cytokines require proteolytic processing for the generation of biological activity. TGF beta is secreted in an inactive form by most cells $(28,29)$, and requires proteolytic processing for its multiple activities to become manifest $(28,29)$. Similarly, TNF $\alpha /$ cachectin may be produced as a promolecule with negligible biological activity that requires proteolytic processing to manifest activity (30). That keratinocytes contain both TGF $\beta$ and TNF $\alpha$ /cachectin mRNA but often lack concordant biological activity attributable to these cytokines (unpublished observation) suggests that keratinocytes may lack these requisite proteases as well.

Recently, it was demonstrated that coculture of endothelial cells and pericytes (but not endothelial cells alone) led to the generation of active TGF $\beta$ (31), suggesting that certain cellcell interactions may activate latent cytokines. It is at present unknown whether coculture of IL- $1 \beta$-producing cells (notably keratinocytes) with cells capable of processing IL- $1 \beta$ yield biologically active IL-1, though preliminary evidence suggests that 
melanocytes possess IL-1 convertase activity. With our report, it would appear that activation of latent cytokines such as IL$1 \beta$ by specific proteases may be an important level of regulation for the generation of cytokine biological activities.

\section{References}

1. Oppenheim, J., E. Kovacs, K. Matsushima, and S. K. Durum. 1986. There is more than one interleukin 1. Immunol. Today. 7:45-56.

2. Dinarello, C. 1984. Interleukin 1. Rev. Infect. Dis. 6:51-95.

3. Elias, J., M. Reynolds, R. Kotloff, and J. Kern. 1989. Fibroblast interleukin 1 beta: synergistic stimulation by recombinant interleukin 1 and tumor necrosis factor and post-translational regulation. Proc. Natl. Acad. Sci. USA. 86:61716175 .

4. Kupper, T. S., D. Ballard, A. O. Chua, J. McGuire, P. Flood, M. Horowitz, R. Langdon, and U. Gubler. 1986. Human keratinocytes contain mRNA indistinguishable from monocyte interleukin 1 alpha and beta mRNA. J. Exp. Med. 69: 2095-2100.

5. Bell, T., C. Harley, D. Stetsko, and D. Sauder. 1987. Expression of mRNA homologous to interleukin 1 in human epidermal cells. J. Invest. Dermatol. 92:809-816.

6. Ansel, J. C., T. A. Luger, D. R. Roop, and J. Mountz. 1988. The expression and modulation of IL-1 alpha in murine keratinocytes. J. Immunol. 140:22742278.

7. Kupper, T. S., A. O. Chua, P. Flood, J. McGuire, and U. Gubler. 1987. Interleukin 1 gene expression in cultured human keratinocytes is augmented by ultraviolet irradiation. J. Clin. Invest. 80:430-436.

8. Blanton, B., T. S. Kupper, J. McDougall, S. Dower. 1989. Regulation of interleukin 1 and its receptor on human keratinocytes. Proc. Natl. Acad. Sci. USA. 86:1273-1277.

9. Kupper, T. S. 1990. The role of epidermal cytokines. In Immunophysiology: The Role of Cells and Cytokines in Immunity and Inflammation. Oxford University Press, New York. 285-305.

10. Cooper, K. C. Hammerberg, O. Baadsgaard, J. Elder, L. Chan, D. Sauder, J. Voorhees, and G. Fisher. IL-1 activity is reduced in psoriatic skin: decreased IL-1 alpha and increased non-functional IL-1 beta. J. Immunol. 144:4593-4598.

11. Kupper, T.S. 1988. Hematopoietic, lymphopoietic, and proinflammatory cytokines produced by keratinocytes. Ann NY Acad. Sci. 548:262-270.

12. Kupper, T. S., F. Lee, N. Birchall, S. Clark, and S. Dower. 1988. Interleukin 1 binds to specific receptors on human keratinocytes and induces granulocyte macrophage colony stimulating factor mRNA and protein: a potential autocrine role for interleukin 1 in epidermis. J. Clin. Invest. 82:1787-1792.

13. Boyce, S. T., and R. G. Ham. 1983. Calcium regulated differentiation of normal human epidermal keratinocytes in chemically defined clonal culture and serum free serial culture. J. Invest. Dermatol. 8:33-34.

14. Kronheim, S. R., M. A. Cantrell, M. C. Deeley, C. March, P. Glackin, D. Anderson, T. Hemenway, J. Merriam, D. Cosmam, and T. Hopp. 1986. Purification to homogeneity of IL-1 beta protein. Biotechnology. 4:1078-1082.

15. Black, R., S. R. Kronheim, M. Cantrell, M. Deely, C. March, K. Prickett,
J. Wignall, P. Conlon, D. Cosman, T. Hopp, and D. Mochizuki. 1988. Generation of biologically active interleukin 1 beta by proteolytic cleavage of the inactive precursor. J. Biol. Chem. 263:9437-9442.

16. Kaye, J., S. Gillis, S. Mizel, E. Shevach, T. Malek, C. Dinarello, L. Lackman, and C. Janeway. 1984. Growth of a cloned helper T cell line induced by a monoclonal antibody for the antigen receptor: interleukin 1 is required for the expression of receptors for interleukin 2. J. Immunol. 133:1339-1345.

17. Mizutani, H., L. May, P. Sehgal, and T. Kupper. 1989. Synergistic interactions of IL- 1 and IL- 6 in T cell activation: mitogen but not antigen receptor induced proliferation of a cloned $\mathrm{T}$ helper cell line is enhanced by exogenous IL-6. J. Immunol. 143:896-901.

18. Mosely, B., D. Urdal, K. Prickett, A. Larsen, D. Cosman, P. Conlon, S. Gillis, and S. K. Dower. 1987. The interleukin 1 receptor binds the human interleukin alpha precursor but not the interleukin 1 beta precursor. J. Biol. Chem. 262:2941-2944.

19. Black, R. A., S. Kronheim, and P. Sleath. 1989. Activation of interleukin1 beta by a co-induced protease. FEBS (Fed. Eur. Biol. Soc.) Lett. 247:386-390.

20. Kostura, M. J., J. Tocci, G. Limjuco, J. Chin, P. Cameron, A. Hillman, N. Chartrain, and J. Schmidt. 1989. Identification of a monocyte specific pre-interleukin 1 beta convertase activity. Proc. Natl. Acad. Sci. USA. 86:5227-5231.

21. Black, R., S. Kronheim, J. Merriam, C. J. March, and T. Hopp. 1989. A pre-Aspartate specific protease from human leukocytes that cleaves pro-interleukin 1 beta. J. Biol. Chem. 264:5323-5326.

22. Young, P., D. Hazuda, and P. Simon. 1988. Human IL-1 $\beta$ is not secreted from hamster fibroblasts when expressed constitutively from transfected cDNA. J. Cell. Biol. 107:447-456.

23. Fuhlbrigge, R., S. Fine, E. Unanue, and D. Chaplin. 1988. Expression of membrane interleukin-1 by fibroblasts transfected with murine pro-interleukin 1 alpha cDNA. Proc. Natl. Acad. Sci. USA. 85:5649-5653.

24. Hazuda, D., J. Lee, and P. R. Young. 1988. The kinetics of IL-1 secretion from activated monocytes: differences between IL- $1 \alpha$ and $\beta$. J. Biol. Chem. 263:8473-8479.

25. Beuscher, H., C. Gunther, and M. Rollinghoff. 1990. IL-1 beta is secreted by activated murine macrophages as biologically inactive precursor. J. Immunol. 144:2179-2183.

26. Conlon, P. J., K. Grabstein, A. Albert, K. Prickett, T. Hopp, and S. Gillis. 1987. Localization of human mononuclear cell interleukin-1. J. Immunol. 139:98-102.

27. Bursten, S. L., R. Locksley, J. Ryan, and D. Lovett. 1988. Acylation of monocyte and glomerular mesangial cell proteins: myristyl acylation of the interleukin 1 precursors. J. Clin. Invest. 82:1479-1488.

28. Wakefield, L., D. Smith, K. Flanders, and M. Sporn. 1988. Latent transforming growth factor beta from human platelets. J. Biol. Chem. 263:7646-7654

29. Miyazano, K., U. Hellman, C. Wernstedt, and C. H. Heldin. 1988. Latent high molecular weight complex of transforming growth factor beta 1. J. Biol. Chem. 263:6407-6415.

30. Antonelli-Oldridge, A., K. Saunders, S. Smith, and P. D'Amore. 1989. An activated form of transforming growth factor beta is produced by cocultures of endothelial cells and pericytes. Proc. Natl. Acad. Sci. USA. 86:4544-4547.

31. Cseh, K., and B. Beutler. 1989. Alternative cleavage of the cachectin/tumor necrosis factor propeptide results in a larger, inactive form of secreted protein. J. Biol. Chem. 264:16256-16260. 